
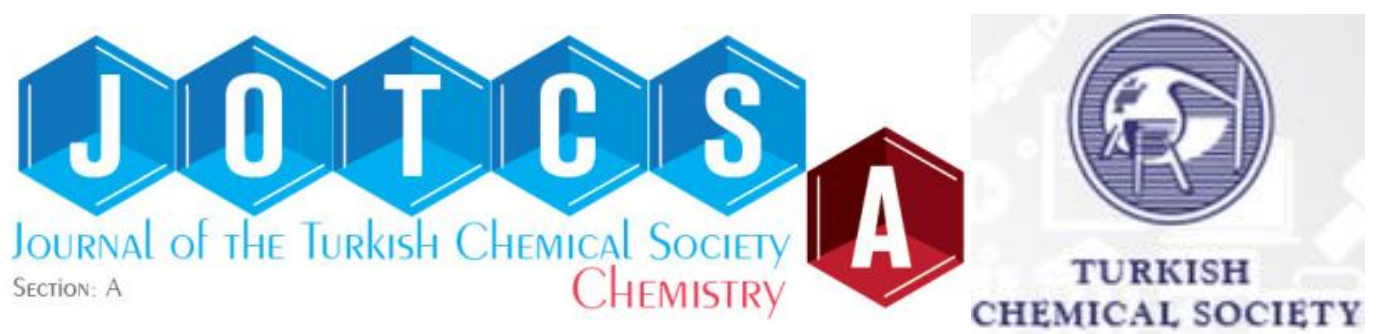

\title{
Synthesis and Characterization of Poly(N-Hydroxymethyl Acrylamide)/Na-Montmorillonite Composites
}

(This manuscript was initially submitted to the $\mathrm{VI}^{\text {th }}$ Congress of Inorganic Chemistry in

Burdur, Turkey, in 2017, and re-evaluated by the JOTCSA editorial staff)

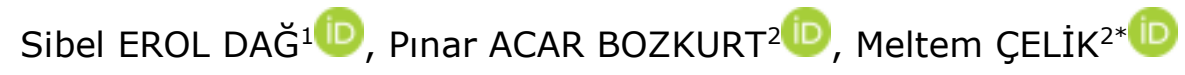

${ }^{1}$ Ankara University, Graduate School of Natural and Applied Sciences, Irfan Baştuğ Street 06110 Dışkapı, Ankara, Turkey.

${ }^{2}$ Ankara University, Department of Chemistry, Faculty of Science, 06100 Tandoğan, Ankara, Turkey.

\begin{abstract}
In this study, the mixtures of N-hydroxymethyl acrylamide (HMAm) monomer and $\mathrm{Na}$-Montmorillonite $(\mathrm{Na}-\mathrm{Mt})$ were polymerized in different ratios in the presence of benzoyl peroxide $\left(\mathrm{Bz}_{2} \mathrm{O}_{2}\right)$ with in-situ radical polymerization to prepare poly $(\mathrm{N}$ hydroxymethyl acrylamide) (PHMAm)/Na-Mt composites. Purified $\mathrm{Na}-\mathrm{Mt}$, and newly prepared composites were characterized with Fourier transform infrared (FTIR) spectroscopy, X-ray diffraction (XRD), scanning electron microscopy (SEM), and thermal analysis (TGA/DTA) techniques. The moisture retention, water uptake, adsorptive properties of the composites was also searched. The XRD patterns demonstrated that the PHMAm matrix intercalated into Na-Mt layers. The PHMAm/Na-Mt composites had much better thermal stability than the pure PHMAm.
\end{abstract}

Keywords: Composite, clay, poly(N-hydroxymethyl acrylamide), benzoyl peroxide, in-situ polymerization.

Submitted: June 06, 2017. Accepted: October 02, 2017.

Cite this: Erol Dağ S, Acar Bozkurt P, Çelik M. Synthesis and Characterization of Poly(NHydroxymethyl Acrylamide)/Na-Montmorillonite Composites. JOTCSA. 2017;4(Sp. is. $1): 39-50$.

DOI: http://doi.org/10.18596/jotcsa.324877.

*Corresponding author. E-mail: mecelik@science.ankara.edu.tr Tel.:+90 3122126720. 


\section{INTRODUCTION}

Polymer/clay composites have been investigated comprehensively in the literature (1-5). Among the multilayer materials, $\mathrm{Na}-\mathrm{Mt}$ is a widely used $1: 1$ aluminosilicate clay mineral with the empirical formula $\mathrm{Si}_{4} \mathrm{Al}_{4} \mathrm{O}_{10}(\mathrm{OH})_{8} .4 \mathrm{H}_{2} \mathrm{O}$, which is chemically related to kaoliniteserpentine group (6). It is found attractable for synthesis of polymer/clay composite because of superior thermal and chemical properties.

Polymer/clay composites exhibit excellent thermal stability, reduced flammability, mechanical and gas barrier properties compared to pure polymers $(7,8)$.

PHMAm has been used in a wide range of industrial applications as protective coatings, adhesives and wood finishes, and textile binders. It is one of most important monomers acting as a crosslinking agent and HMAm is easily polymerized because of its hydrophilic nature (9). In addition to this, low thermal and mechanical features, especially thermal stability, is necessary to be improved. Furthermore, PHMAm is a hydrophilic and non-ionic polymer with hydroxyl groups on the side chain coating a hydrophobic carbon-carbon spine.

In the present work, PHMAm/unmodified Na-Mt composites were prepared to increase the thermal stability of PHMAm via the synthesis using multi-layered materials like clay.

A considerable number of studies on polymer/clay composites exist in the literature, but there are very few research work available on preparation and characterization of PHMAm/unmodified Na-Mt composites. Also, the present study explains the morphology and thermal properties of the newly synthesized composites.

\section{EXPERIMENTAL}

\section{Materials}

Reagent grade $\mathrm{N}$-hydroxymethyl acrylamide (HMAm) (Merck) was used without further purification. A free radical initiator, benzoyl peroxide $\left(\mathrm{Bz}_{2} \mathrm{O}_{2}\right)$ (Merck) was twice purified by recrystallization from methanol and chloroform mixture. The clay used in this study was Na-Montmorillonite (Na-Mt) provided from Reşadiye (Tokat/Turkey) and it was purified prior to use (10). The specific surface and the cation exchange capacity (CEC) of the clay sample are $67.56 \mathrm{~m}^{2} / \mathrm{g}$, and $109 \mathrm{meq} / 100 \mathrm{~g}$, respectively. No pre-treatment was applied to the other chemicals used. 


\section{Composite synthesis by in situ radical polymerization}

PHMAm/Na-Mt composites were synthesized by in situ free radical polymerization in aqueous medium $(11,12)$.

$1 \mathrm{~g}$ of $\mathrm{Na}-\mathrm{Mt}$ was dispersed in $24 \mathrm{~mL}$ of distilled water in a $100 \mathrm{~mL}$ pyrex glass tube and was stirred at a rate of $100 \mathrm{rpm}$ for overnight at room temperature for each polymerization. The HMAm and the aqueous Na-Mt suspension were mixed at different weight ratios (Table 1). $1 \mathrm{~mL} \mathrm{Bz} 2 \mathrm{O}_{2}$ solution in acetone $\left(3.59 \times 10^{-3} \mathrm{~mol} / \mathrm{L}\right)$ was added to these mixtures. The mixtures thus obtained were polymerized in ultrasonic bath (Bandelin Sonalex RK $100 \mathrm{H}$, Germany) at $85^{\circ} \mathrm{C}$ for $2 \mathrm{~h}$. The resulting composites were dried in a vacuum oven at 30 ${ }^{\circ} \mathrm{C}$, and weighed.

Table 1: Composite samples and polymerization conditions ${ }^{a}$.

\begin{tabular}{ll}
\hline Composite samples & $\begin{array}{l}\text { Monomer amount } \\
\text { (mass \%) }\end{array}$ \\
\hline PHMAm/Na-Mt1 & 33.33 \\
PHMAm/Na-Mt2 & 50.00 \\
PHMAm/Na-Mt3 & 60.00 \\
PHMAm/Na-Mt4 & 66.67 \\
PHMAm/Na-Mt5 & 71.43 \\
PHMAm/Na-Mt6 & 75.00 \\
PHMAm/Na-Mt7 & 77.78 \\
PHMAm/Na-Mt8 & 80.00 \\
\hline
\end{tabular}

PHMAm: poly(N-hydroxymethyl acrylamide); Mt: montmorillonite.

${ }^{\mathrm{a}}\left[\mathrm{Bz}_{2} \mathrm{O}_{2}\right]: 3.59 \times 10^{-3} \mathrm{~mol} / \mathrm{L}$, temperature: $85^{\circ} \mathrm{C}$, time: $2 \mathrm{~h}$.

\section{Characterization of the prepared composites}

Fourier transform infrared (FT-IR) spectra of Na-Mt sample and PHMAm/Na-Mt composites were recorded in $\mathrm{KBr}$ pellets on a Bruker IFS 66/S Model FTIR spectrometer in the region of $400-4000 \mathrm{~cm}^{-1}$.

The X-ray diffraction (XRD) patterns were obtained with a diffractometer Rigaku D/MAX 2200 using CuKa irradiation ( $\lambda=1.5418 \AA$ ), a scanning speed of $0.15 \%$ min within the range of $2 \theta=2-40^{\circ}$. The Na-Mt and composites were powdered and dried in a vacuum oven for XRD experiments. 
Thermal analysis runs were performed simultaneously on a DTA-TG apparatus (DTG-60H Model) under dynamic nitrogen atmosphere at a heating rate of $10{ }^{\circ} \mathrm{C} / \mathrm{min}$ (range: $25-800$ $\left.{ }^{\circ} \mathrm{C}\right)$. $\mathrm{a}-\mathrm{Al}_{2} \mathrm{O}_{3}$ was taken as the reference material.

The surface morphology of pure $\mathrm{Na}-\mathrm{Mt}$ and composites was examined by using a Quanta 400F Field Emission microscope. All samples were coated with gold thin layer prior to analysis.

The specific surface area and micro-mesopore size of Na-Mt and composites were determined by physical adsorption of nitrogen with the Brunauer-Emmett-Teller (BET) method at $77 \mathrm{~K}$ using Quantachrome Nova 2200 analyzer. All samples were outgassed at $150{ }^{\circ} \mathrm{C}$ for $4 \mathrm{~h}$ prior to $\mathrm{N}_{2}$ physisorption.

The dry samples in the form of pellet were weighed. Pellets were conditioned at $25{ }^{\circ} \mathrm{C}$ in a medium of $100 \%$ humidity for $24 \mathrm{~h}$ for the retained moisture measurements. The percentage moisture retention was calculated from the difference between the weights of the conditioned and unconditioned samples (i.e. moisture retention $\%=\left(W_{2}-W_{1}\right) / W_{1} \times 100$, where $W_{1}$ and $W_{2}$ are the weights of the conditioned and unconditioned samples, respectively) $(5,11,12)$.

The dry samples in the form of pellets were weighed, $W_{1}$ and then kept in distilled water for $2 \mathrm{~h}$ at $25^{\circ} \mathrm{C}$. After immersion, the wet samples were wiped using filter paper and reweighed immediately, $W_{2}$. The percentage water uptake of samples was determined from the formula $\left(W_{2}-W_{1}\right) / W_{1} \times 100(5,11,12)$.

\section{RESULTS AND DISCUSSION}

\section{$X$-ray diffraction analysis}

Figure 1(a-f) illustrates the XRD patterns of the Na-Mt, pure PHMAm and PHMAm/Na-Mt composites, prepared using various with HMAm monomer contents. Bragg's equation $(\mathrm{d}=\mathrm{n} \lambda / 2 \sin \theta)$ was used to compute the crystallographic spacing $(d)$ for the examined bentonite samples. The diffraction peak of the Na-Mt appearing at $2 \theta=7.46^{\circ}$ corresponds to a $d_{001}$ spacing of $1.18 \mathrm{~nm}$ (Table 2). In the XRD patterns, the specific crystalline peak of composites was shifted to lower angles because of the intercalation of PHMAm between the Na-Mt layers [Figure $1(\mathrm{~b}-\mathrm{e})$ ]. The Na-Mt interlayer distance changed from $1.18 \mathrm{~nm}$ to $1.97 \mathrm{~nm}$ until $50.00 \%$ monomer content. The increase by $0.79 \mathrm{~nm}$ of the $d_{001}$ value indicates that the PHMAm molecules are intercalated between the interlayer of the clay. However, no more expansion in the interlayer spacing was observed at higher HMAm 
content. It can be concluded from this result that the PHMAm molecules penetrating through the interlayer space of the clay and expanding the interlayer spacing proves the synthesis of the PHMAm/Na-Mt composites through direct intercalation $(2,13,14)$.

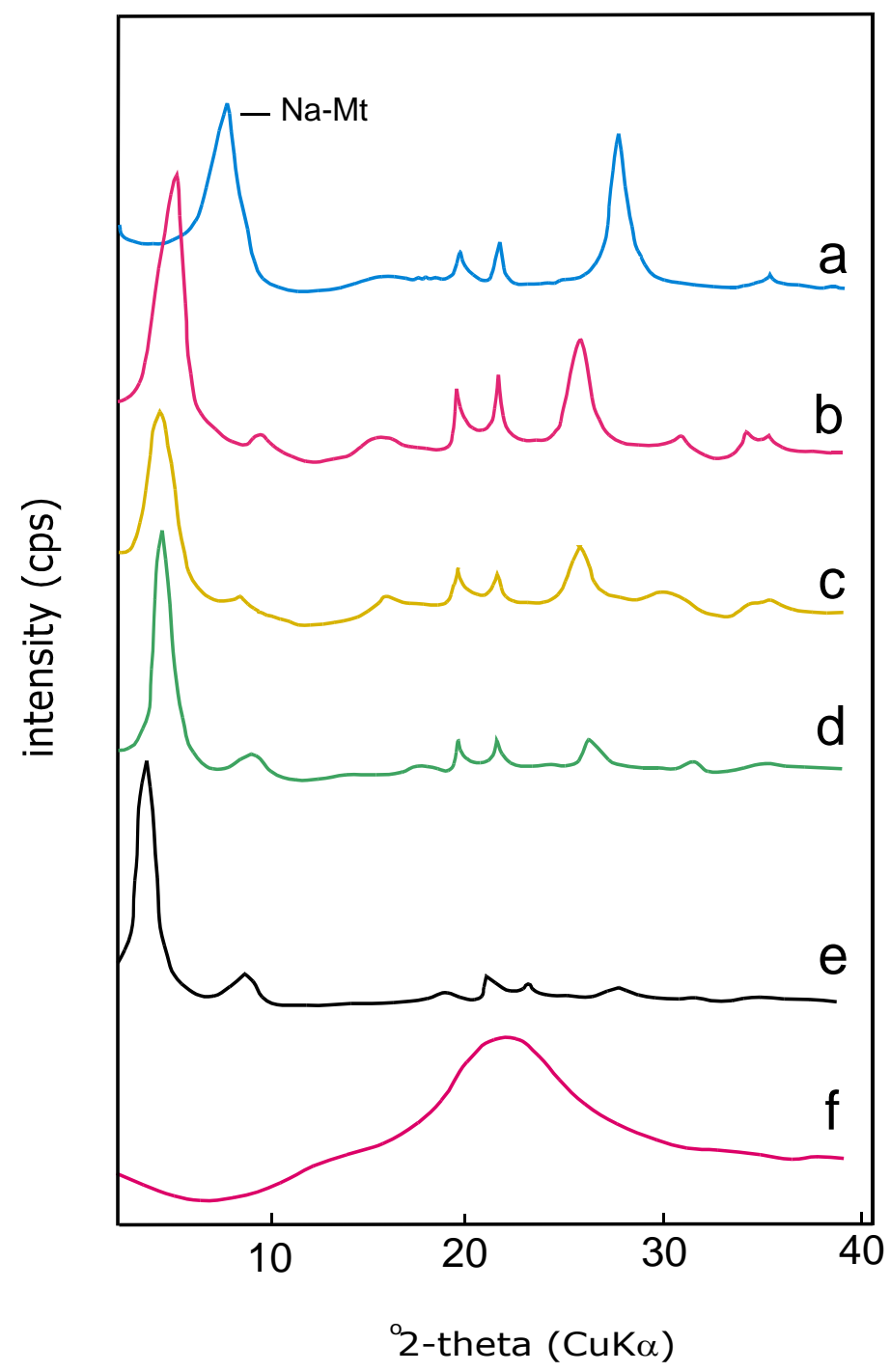

Figure 1: XRD patterns of (a) Na-Mt, (b) PHMAm/Na-Mt2, (c) PHMAm/Na-Mt4, (d) PHMAm/Na-Mt6, (e) PHMAm/Na-Mt8, and (f) pure PHMAm.

Table 2: XRD parameters for Na-Mt and PHMAm/Na-Mt composites.

\begin{tabular}{lll}
\hline Sample & $\left.\mathbf{2 \theta} \mathbf{(}^{\circ}\right)$ & $\mathbf{d}_{\mathbf{0 0 1}}(\mathbf{n m})$ \\
\hline Na-Mt & 7.46 & 1.18 \\
PHMAm/Na-Mt2 & 4.47 & 1.97 \\
PHMAm/Na-Mt4 & 5.15 & 1.72 \\
PHMAm/Na-Mt6 & 4.95 & 1.78 \\
PHMAm/Na-Mt8 & 4.52 & 1.95 \\
Pure PHMAm & - & - \\
\hline
\end{tabular}

PHMAm: poly(N-hydroxymethyl acrylamide); Mt: montmorillonite. 


\section{FT-IR spectral analysis}

The FTIR spectra of Na-Mt, pure PHMAm, and PHMAm/Na-Mt7 are shown in Figure 2(a-c). In the FTIR spectrum of PHMAm, the strong single peak at $3281 \mathrm{~cm}^{-1}$ is assigned to the stretching vibration of $\mathrm{N}-\mathrm{H}$ groups. There are also bands corresponding to the $\mathrm{CO}$ amide groups at $1645 \mathrm{~cm}^{-1}$ and $\mathrm{C}-\mathrm{N}$ groups at $1531 \mathrm{~cm}^{-1}$. The characteristic features of $\mathrm{Na}-\mathrm{Mt}$ at $3630 \mathrm{~cm}^{-1}$ (O-H stretching), $470 \mathrm{~cm}^{-1}(\mathrm{Mg}-\mathrm{O}), 1040 \mathrm{~cm}^{-1}$ and $515 \mathrm{~cm}^{-1}$ (Al-O-Si) are observed in the composite spectra $(6,9,13,15)$. These spectra indicate the interaction between $\mathrm{Na}-\mathrm{Mt}$ and polymer matrix.

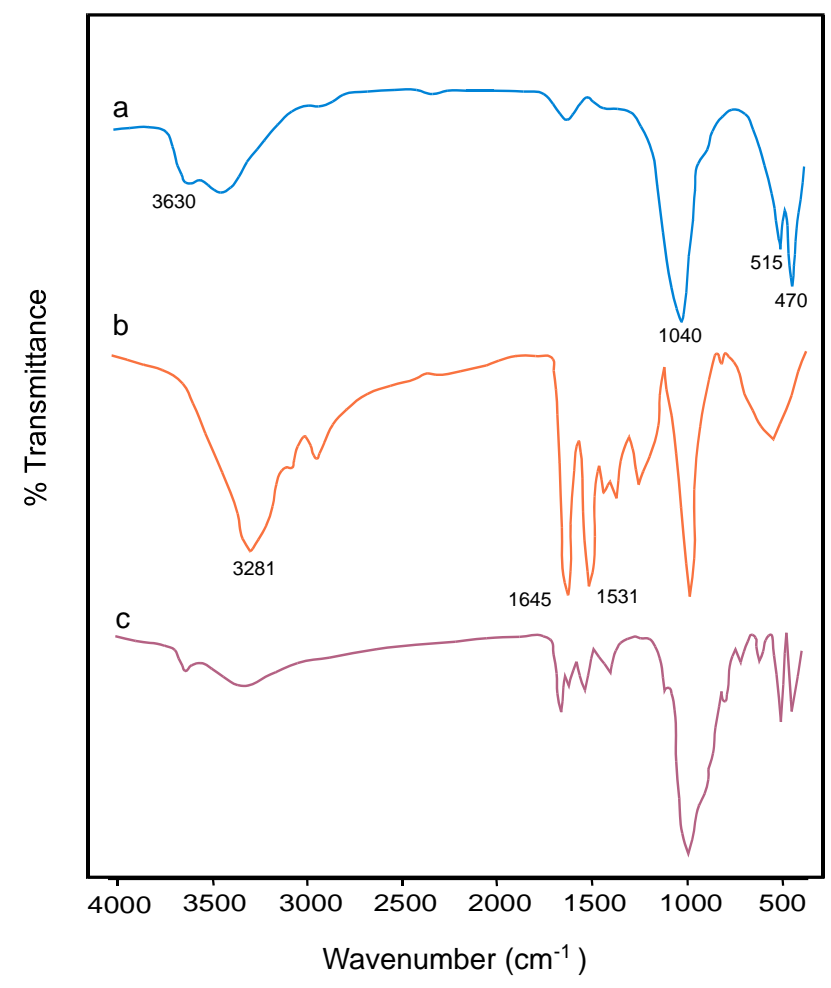

Figure 2: FTIR spectra of (a) Na-Mt, (b) pure PHMAm, and (c) PHMAm/Na-Mt7.

\section{SEM analysis}

Figure 3(a-d) shows the SEM images of Na-Mt, pure PHMAm, and PHMAm/Na-Mt3, and PHMAm/Na-Mt7 composites, respectively. The layered structure of the clay before the polymerization and bright and smooth surface of PHMAm are shown in Figures 3(a) and $3(b)$, respectively. The clay layers have been uniformly dispersed on the polymer matrix following the PHMAm polymerization process on the Na-Mt layers where the morphology of the synthesized composite displays a spongy and porous structure (Figure 3(c) and (d)). This observation is in well conformity with the previous XRD results obtained on similar clay/polymer composites $(2,13,16,17)$. 

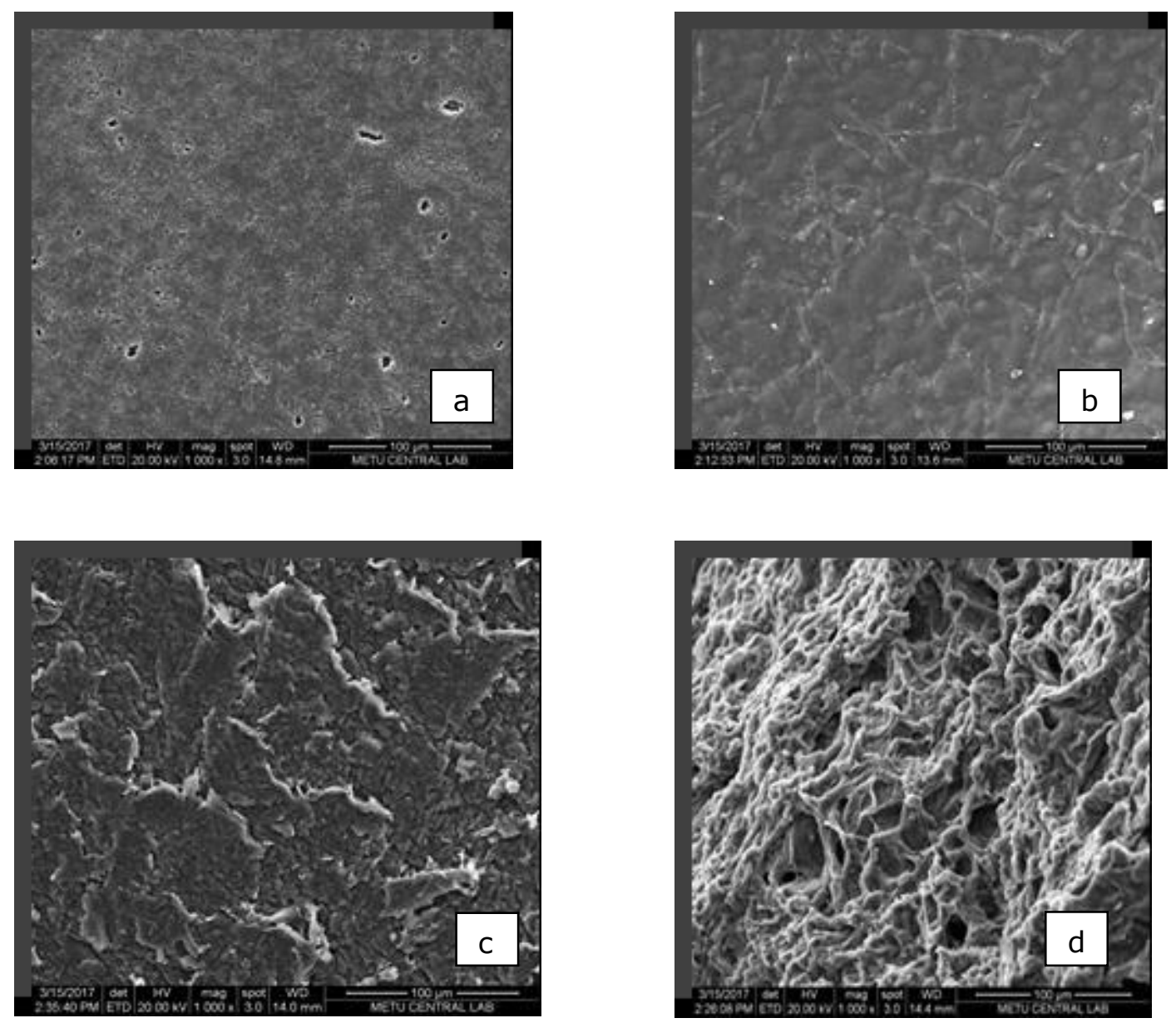

Figure 3: SEM images of (a) Na-Mt , (b) pure PHMAm (c) PHMAm/Na-Mt3, and (d) PHMAm/Na-Mt7.

\section{Thermal analysis data}

The thermograms of Na-Mt, pure PHMAm, PHMAm/Na-Mt3, and PHMAm/Na-Mt7 are presented in Figure 4(a-d). The weight losses observed at temperatures lower than $125^{\circ} \mathrm{C}$ on the TGA curve of $\mathrm{Na}-\mathrm{Mt}$ indicate the elimination of the moisture and physisorbed water species in the structure. At higher temperatures, weight losses occurred due to the dehydroxylation of $\mathrm{Na}-\mathrm{Mt}$. The total weight loss by $20.82 \%$ of $\mathrm{Na}-\mathrm{Mt}$ is noticeable up to the temperature of $800{ }^{\circ} \mathrm{C}$ showing high thermal stability of the pure clay $(2,6,15)$.

The removal of adsorbed water from pure PHMAm occurs with a small weight loss at temperatures below $150^{\circ} \mathrm{C}$ (Figure $4(\mathrm{~b})$ ). The degradation temperature of pure PHMAm is $263.07^{\circ} \mathrm{C}$, and it is almost completely degraded at $800^{\circ} \mathrm{C}$. As a result, pure PHMAm should have lower thermal stability than to Na-Mt.

The PHMAm/Na-Mt3 composite has a degradation temperature $\left(339.39^{\circ} \mathrm{C}\right)$ which is higher by $76.32{ }^{\circ} \mathrm{C}$ than that of pure PHMAm, and shows a weight loss of $25.32 \%$ at $800{ }^{\circ} \mathrm{C}$. This 
weight loss is smaller than that seen at $150^{\circ} \mathrm{C}$ which is due to the desorption of adsorbed water [Fig. 4(c)]. However, the weight loss increased further up to 77.78 wt \% in parallel with the HMAm content, e.g., the PHMAm/Na-Mt7 composite had a lower decomposition temperature $\left(320^{\circ} \mathrm{C}\right.$ ) and exhibited a weight loss by $74.63 \%$ at $800{ }^{\circ} \mathrm{C}$ depending on the decrease of the clay content in the sample. Similarly, a small weight loss seen below 120 ${ }^{\circ} \mathrm{C}$ may be ascribed to the removal of adsorbed water [Fig. 4(d)]. As a result, incorporation of PHMAm into Na-Mt would be expected to increase the thermal stabilities of the PHMAm/Na-Mt3 and PHMAm/Na-Mt7 composites in comparison with pure PHMAm. This enhanced thermal stability of the PHMAm/Na-Mt composites may be given to Na-Mt acting as a barrier against heat flow (15-18).

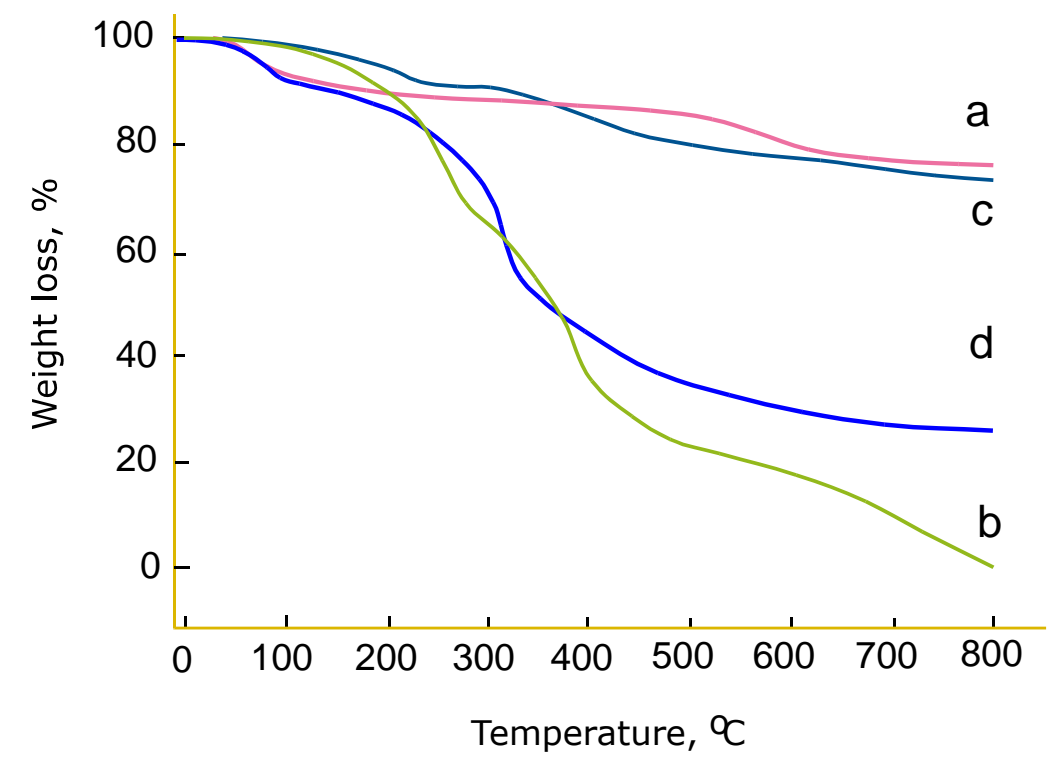

Figure 4: TGA curves of (a) Na-Mt , (b) pure PHMAm, (c) PHMAm/Na-Mt3, and (d) PHMAm/Na-Mt7 composite.

\section{Surface area measurements and micro-mesopore volumes}

The determined micro-mesopore volumes and surface areas of Na-Mt and PHMAm/Na-Mt composites using adsorption and desorption isotherms are listed in Table 3.

Table 3. The BET specific surface areas $(A)$ and specific micro-mesopore volumes $(V)$ of NaMt and PHMAm/Na-Mt composites.

\begin{tabular}{lll}
\hline Sample & $(\mathbf{A}), \mathbf{~ m}^{\mathbf{2}} \mathbf{g}^{-\mathbf{1}}$ & $\mathbf{( V ) \times 1 0 ^ { 3 }}, \mathbf{c m}^{\mathbf{3}} \mathbf{g}^{-\mathbf{1}}$ \\
\hline Na-Mt & 67.56 & 111.0 \\
PHMAm/Na-Mt1 & 10.32 & 0.21 \\
PHMAm/Na-Mt2 & 5.79 & 0.12 \\
PHMAm/Na-Mt3 & 4.53 & 0.10
\end{tabular}

PHMAm: poly(N-hydroxymethyl acrylamide); Mt: Montmorillonite. 
It could be as expected that the Na-Mt would exhibit higher BET surface area and micromesopore volume than PHMAm/Na-Mt composites. The BET surface area and micromesopore volume of Na-Mt were $67.56 \mathrm{~m}^{2} \mathrm{~g}^{-1}$ and $111.0 \times 10^{-3} \mathrm{~cm}^{3} \mathrm{~g}^{-1}$, respectively. Table 3 shows that these values decreased significantly down to $10.32 \mathrm{~m}^{2} \mathrm{~g}^{-1}$ and $0.21 \times 10^{-3} \mathrm{~cm}^{3} \mathrm{~g}^{-1}$ for PHMAm/Na-Mt1, $5.79 \mathrm{~m}^{2} \mathrm{~g}^{-1}$ and $0.12 \times 10^{-3} \mathrm{~cm}^{3} \mathrm{~g}^{-1}$ for PHMAm/Na-Mt2, and $4.53 \mathrm{~m}^{2} \mathrm{~g}^{-1}$ and $0,10 \times 10^{-3} \mathrm{~cm}^{3} \mathrm{~g}^{-1}$ for PHMAm/Na-Mt3, respectively. Lower surface area of PHMAm/NaMt composites than that of $\mathrm{Na-Mt} \mathrm{(Table} 3$ ) suggests that the latter sample may have considerable amount of the blocked small- and medium-size pores by PHMAm (19-22).

\section{Measurements of moisture retention and water uptake}

The moisture retention and water uptake values of $\mathrm{Na}-\mathrm{Mt}$ and PHMAm/Na-Mt composites decreased with PHMAm content as shown in Figures 5 and 6 . It was observed that moisture retention of the composites decreased remarkably, but water uptake decreased gradually.

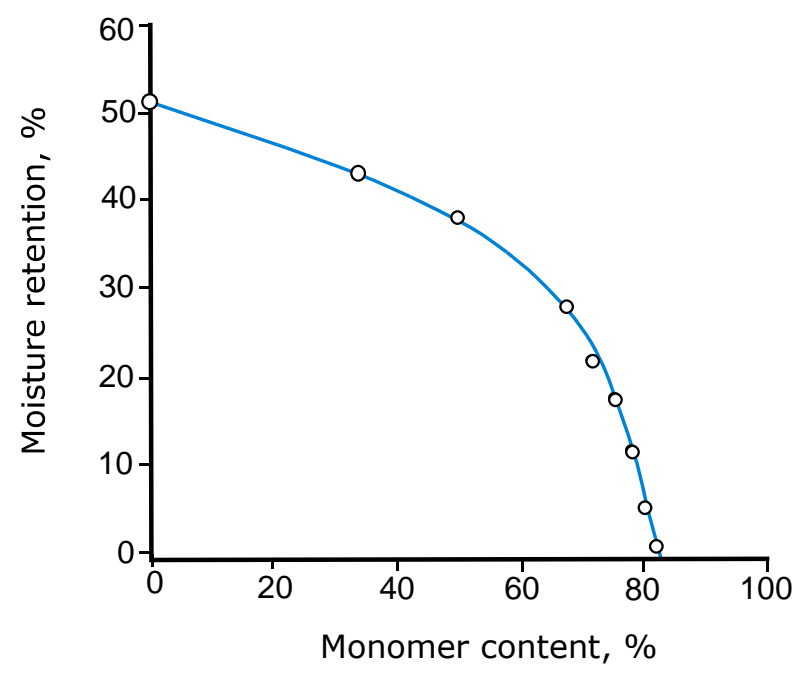

Figure 5. Percentage moisture retention values of $\mathrm{Na}-\mathrm{Mt}$ and PHMAm/Na-Mt composites.

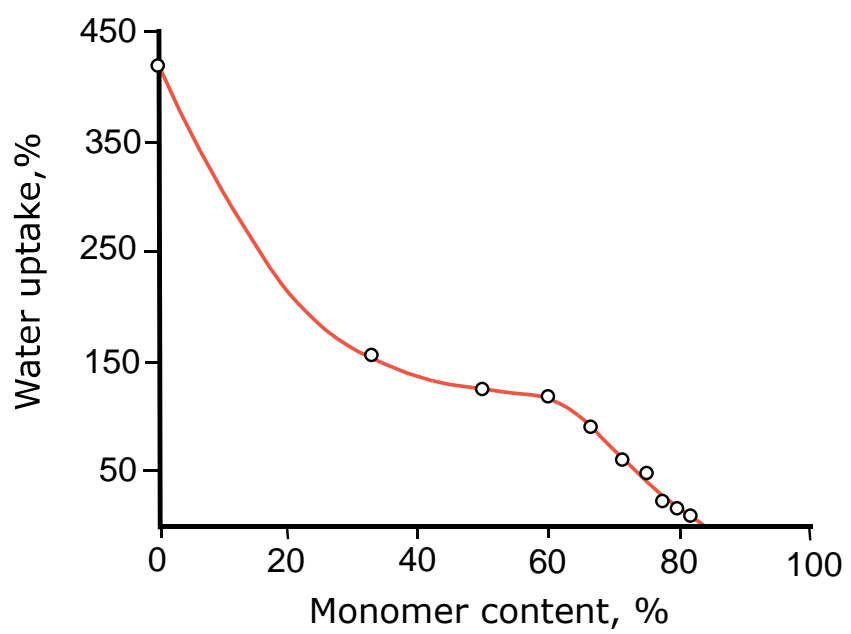

Figure 6. Percentage water uptake values of $\mathrm{Na}-\mathrm{Mt}$ and PHMAm/Na-Mt composites. 
The decreases in moisture retention and water uptake can be attributed to the presence of the limited amount of clay reatained by the composites, which reflects that the polymer species introduced into the layers of $\mathrm{Na}$-Mt reaches a certain extent in the duration of the formation of a cross linked structure which prevents the insertion of water molecules. Water resistance of the composites can be greatly developed as an outcome of this effect $(23,24)$.

\section{CONCLUSIONS}

PHMAm/Na-Mt composites were successfully prepared by in situ free radical polymerization. The resulting composites showed higher thermal stability than pure PHMAm and Na-Mt clay induced the thermal stability. The PHMAm/Na-Mt3 composite has a degradation temperature which is higher by $76.32{ }^{\circ} \mathrm{C}$ than that of pure PHMAm. The resultant composites had a distinct intercalated morphology. XRD data demonstrated that interlayer distance of $\mathrm{Na}-\mathrm{Mt}$ increased with $\mathrm{N}$-hydroxymethyl acrylamide amount up to $50.00 \mathrm{wt} \%$ and then no further increase of the interlayer distance at higher HMAm content was observed. Adsorptive, moisture retentions and water uptake values of composites obviously decreased in comparison with that of $\mathrm{Na}-\mathrm{Mt}$.

\section{ACKNOWLEDGEMENT}

Research Foundation of Ankara University is acknowledged for the financial support to this work under the Project Number 16L0430012. We are grateful to Professor Müşerref Önal for her kindness of donation of clay sample.

\section{REFERENCES}

1. Akat H, Taşdelen MA, Du Prez F, Yagci Y. Synthesis and Characterization of Polymer/clay Nanocomposites by Intercalated Chain Transfer Agent. European Polymer Journal.2008 Apr; $44: 1949-54$.

2. Çelik M, Önal M. Preparation and Characterization of Intercalated Polymethacrylamide/NaMontmorillonite Nanocomposites. Journal of Macromolecular Science, Part A: Pure and Applied Chemistry. 2006 Feb; 43(6):933-43.

3. Choi HJ, Kim JW, Joo J, Kim BH. Synthesis and Electrorheology of Emulsion Intercalated PANI-clay Nanocomposite. Synthetic Metals. 2001 Mar; 121:1325-26.

4. Anbarasan R, Arvind P, Dhanalakshmi V. Synthesis and Characterization of PolymethacrylamideClay Nanocomposites. Journal of Applied Polymer Science. 2011 Feb; 121(1):563-73.

5. Koç Z, Çelik M, Önal M, Sarıkaya Y, Öner Y, Açık L. Study on the Synthesis and Properties of Polyacrylamide/Na-montmorillonite Nanocomposites. Journal of Composite Materials. 2014 May; 48(4):439-46. 
6. Caglar, B., Afsin, B., Tabak, A., Eren, E. Characterization of the Cation-exchanged Bentonites by XRPD, ATR, DTA/TG Analyses and BET Measurement. Chemical Engineering Journal. 2009 Jul; $149(1-3): 242-48$.

7. Kumar S, Jog JP, Natarajan U. Preparation and Characterization of Poly(methylmethacrylate)-Clay Nanocomposites via Melt Intercalation: The Effect of Organoclay on the Structure and Thermal Properties. Journal of Applied Polymer Science. 2003 May; 89(5):1186-94.

8. Gao, F. Clay/Polymer Composites: the Story. Materials Today. 2004 Nov; 7(11):50-55.

9. Kraisiri D, Chantarasiri N, Pimpan V. Thermal Behavior of Poly(N-hydroxymethyl acrylamide) Synthesized by Inverse Emulsion Polymerization. Academic Journal of Science. 2012 May; 1(2):18388.

10. Önal M, Sarıkaya Y, Alemdaroğlu T, Bozdoğan İ. Isolation and Characterization of a Smectite as a Micro-Mesoporous Material from a Bentonite. Turkish Journal of Chemistry. 2003 Jun; 27(6):68384.

11. Koç Z, Çelik M, Önal M, Sarıkaya Y, Mogulkoç Y. Preparation and characterization of poly(2hydroxyethyl methacrylate)/Na-montmorillonite Intercalated Nanocomposites. Journal of Polymer Engineering. 2013 Jan; 33(1):27-32.

12. Çelik M, Önal M. Polythiophene/Na-montmorillonite Composites via Intercalative Polymerization. Journal of Thermoplastic Composite Materials. 2014 Feb; 27(2):145-59.

13. Önal M, Çelik M. Polymethacrylamide/Na-montmorillonite Nanocomposites Synthesized by Freeradical Polymerization. Materials Letters. 2006 August; 60(1):48-52.

14. Tong $X$, Zhao $H$, Tang $T$, Feng $Z$, Huang B. Preparation and Characterization of Poly(ethylacrylate)/Bentonite Nanocomposites by In Situ Emulsion Polymerization. Journal of Polymer Science Part A: Polymer Chemistry. 2002 Apr; 40(11):1706-11.

15. Koksal, E., Afsin, B., Tabak, A., Caglar, B. Structural Characterization of Aniline-Bentonite Composite by FTIR, DTA/TG, and PXRD Analyses and BET Measurement._ Spectroscopy Letters._2011 Feb; 44(2):77-82.

16. Zhang $\mathrm{X}, \mathrm{Xu} \mathrm{R}, \mathrm{Wu} \mathrm{Z}$, Zhou C. The Synthesis and Characterization of Polyurethane/clay Nanocomposites. Polymer International. 2003 Apr; 52:790-94.

17. Tiwari RR, Natajaran U. Thermal and Mechanical Properties of Melt Processed Intercalated Poly(methylmethacrylate)-organoclay Nanocompositesover a Wide Range of Filler Loading. Polymer International. 2008 Dec; 57(5):738-43.

18. Peighambardoust SJ, Pourabbas B. Synthesis and Characterization of Conductive Polypyrrole/Montmorillonite Nanocomposites via One-pot Emulsion Polymerization. Macromolecular Symposia. 2007 Feb; 247(1):99-109.

19. Samrana K, Shahzada A, Jiri P, Yogesh MJ. Polyaniline-sodium Montmorillonite Clay Nanocomposites: Effect of Clay Concentration on Thermal, Structural, and Electrical Properties. Journal of Materials Science. 2012 Jan; 47:420-28.

20. Çelik M, Önal M. Synthesis and Characterization of Poly(glycidyl methacrylate)/Namontmorillonite Nanocomposites. Journal of Applied Polymer Science. 2004 Nov; 94(4):1532-38.

21. Sur GS, Lyu SG, Chang JH. Synthesis and LCST Behavior of Thermosensitive Poly (Nisopropylacrylamide)-Clay Nanocomposites. Journal of Industrial and Engineering Chemistry. 2003 Jan; 9(1):58-62.

22. Boukerma K, Piquemal JY, Chehimi MM, Mravcakova M, Omastova M, Beaunier P. Synthesis and Interfacial Properties of Montmorillonite/polypyrrole Nanocomposites. Polymer. 2006 Jan; 47(2):569-76. 
23. Han B, Cheng A, Ji G, Wu S, Shen J. Effect of Organophilic Montmorillonite on Polyurethane/montmorillonite Nanocomposites. Journal of Applied Polymer Science. 2004 Feb; 91(4):2536-42.

24. Low HY, Liu TX, Loh WW. Moisture Sorption and Permeation in Polyamide 6/clay Nanocomposite Films. Polymer International. 2004 Dec; 53(12):1973-78. 